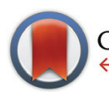

CrossMark \&lick for updates

Cite this: Dalton Trans., 2016, 45 1103

Received 27th August 2015, Accepted 23rd November 2015 DOI: $10.1039 / c 5 d t 03314 d$ www.rsc.org/dalton

\section{Sodalite-like rare-earth carbonates: a study of structural transformation and diluted magnetism $\uparrow$}

\begin{abstract}
Yanyan Wang, ${ }^{a}$ Tian Han, ${ }^{a}$ You-Song Ding, ${ }^{a}$ Zhiping Zheng ${ }^{b}$ and Yan-Zhen Zheng ${ }^{\star a}$
A series of novel rare earth carbonates, $\mathrm{RE}_{3}(\mathrm{OH})_{6}\left(\mathrm{CO}_{3}\right) \mathrm{Cl}(\mathrm{RE}=\mathrm{Dy}, \mathrm{Er}, \mathrm{Y})$, with sodalite-like (SOD-like) zeolite topologies have been successfully synthesized by introducing an appropriate amount of $\mathrm{CO}_{3}{ }^{2-}$ from $\mathrm{NaCO}_{3}$ or atmospheric carbon dioxide as a template. Single-crystal X-ray diffraction reveals that the structure consists of the $\mathrm{RE}_{3}(\mathrm{OH})_{6}{ }^{3+}$ cationic framework with a SOD-like topology built from vertexsharing $\left[\mathrm{RE}_{4}\left(\mu_{3}-\mathrm{OH}\right)_{4}\right]$ cubes. The $\mathrm{CO}_{3}{ }^{2-}$ anions seal the 6-ring opening and $\mathrm{Cl}^{-}$anions situated in the channels to achieve charge balance. After calcination at $370{ }^{\circ} \mathrm{C}$, the compound $\mathrm{RE}_{3}(\mathrm{OH})_{6}\left(\mathrm{CO}_{3}\right) \mathrm{Cl}$ in situ transforms into a new phase formulated as $\mathrm{RE}_{3} \mathrm{O}_{4} \mathrm{Cl}$. Interestingly, the structure of $\mathrm{RE}_{3} \mathrm{O}_{4} \mathrm{Cl}$ represents a new SOD-like open framework, associated with the removal of the $\mathrm{CO}_{3}{ }^{2-}$ from $\mathrm{RE}_{3}(\mathrm{OH})_{6}\left(\mathrm{CO}_{3}\right) \mathrm{Cl}$. The samples are characterized by thermogravimetric analysis (TGA), elemental analysis, $\mathrm{X}$-ray photoelectron spectroscopy and magnetic studies. Furthermore, single-molecule magnet behaviours can be observed for the diluted samples of $D y_{0.0068} \mathrm{Y}_{2.9932}(\mathrm{OH})_{6}\left(\mathrm{CO}_{3}\right) \mathrm{Cl}$ and $\mathrm{Dy} \mathrm{y}_{0.0068} \mathrm{Y}_{2.9932} \mathrm{O}_{4} \mathrm{Cl}$ with a $\mathrm{Dy} / \mathrm{Y}$ molar ratio of up to $1 / 440$ as well as $\mathrm{Er}_{0.19} \mathrm{Y}_{2.81}(\mathrm{OH})_{6}\left(\mathrm{CO}_{3}\right) \mathrm{Cl}$ with an $\mathrm{Er} / \mathrm{Y}$ ratio of $1 / 15$, showing dominant single-ion effects.
\end{abstract}

\section{Introduction}

Open framework materials with porous structures, especially with zeolitic topologies, have attracted considerable attention for their permanent porosity, excellent thermal and chemical stabilities, and are widely used in industrial applications. ${ }^{1}$ Among the 229 zeolitic topologies, the traditional zeolite is built exclusively from $\mathrm{TO}_{4}$ tetrahedra, with the $\mathrm{T}$ atoms being from the main group or transition metal group, such as $\mathrm{Si}^{4+}$, $\mathrm{Al}^{3+}, \mathrm{Ge}^{4+}, \mathrm{Zn}^{2+}$, etc. ${ }^{2}$ Rare earth (RE) elements are ideal candidates to incorporate into open framework materials for the exploration of new applications, since they contain unique properties in photoluminescence, magnetism and so on. ${ }^{3}$ Several microporous lanthanide silicates that are built from $\mathrm{SiO}_{4}$ tetra-

\footnotetext{
${ }^{a}$ Centre for Applied Chemical Research, Frontier Institute of Science and Technology, and MOE Key Laboratory for Nonequilibrium Synthesis and Modulation of Condensed Matter, College of Science, Xi'an Jiaotong University, Xi'an 710054, China. E-mail: zheng.yanzhen@xjtu.edu.cn; Fax: (+)86-29-83395366

${ }^{b}$ Department of Chemistry and Biochemistry, University of Arizona, Tucson, Arizona 85721, USA

$\dagger$ Electronic supplementary information (ESI) available: Crystal data and structure refinement and selected bond lengths $[\AA]$ for 1-3 and 1-c; thermal ellipsoids for 1-3 and 1-c; 3-dimensional structure of 1-c; PXRD patterns for all samples; TGA curve for 1; XPS for $\mathbf{1}$ and 1-c; temperature dependence of $M v$ s. $H$, in-phase $\left(\chi^{\prime}\right)$ and out-of-phase $\left(\chi^{\prime \prime}\right)$ ac susceptibility curves of 1, 2, 1d, 2d, 1-c and 1d-c; crystallographic data for 1-3 and 1-c (CIF). CCDC 1416221-1416224 for 1-3 and 1-c. For ESI and crystallographic data in CIF or other electronic format see DOI: $10.1039 / \mathrm{c} 5 \mathrm{dt} 03314 \mathrm{~d}$
}

hedra and $\mathrm{LnO}_{n}(n \geq 6)$ polyhedra have been successfully prepared. $^{4}$

Moreover, RE ions have become attractive candidates for constructing new single-ion magnets (SIMs) as well as singlemolecular magnets (SMMs), because most of them have a large unquenched orbital angular momentum, which may bring significant anisotropy to the system. ${ }^{5}$ Synthetic efforts along this line have led to the discovery of many materials exhibiting SIM behaviour, expanding to lanthanide clusters and even complexes with 3-dimensional (3D) metal-organic framework structures. ${ }^{6}$ However, few magnetic studies are focused on RE inorganic materials with 3D open framework structures. $^{7}$

The synthesis of traditional open framework materials is typically carried out in a gel medium under solvothermal conditions by using alkali metal ions or organic amines as templates or structure-directing agents (SDAs) ${ }^{8}$ However, this strategy is not suitable for the synthesis of RE open frameworks, as the RE ions have variable and high coordination numbers as well as poor directionality, which is significantly different from transition metal ions. ${ }^{9}$

For the design of RE open frameworks, it is worthwhile to refer to the synthesis of transition or lanthanide-based clusters ${ }^{10}$ in which the carbonate $\left(\mathrm{CO}_{3}{ }^{2-}\right)$ anion is an extremely versatile bridging ligand. Aside from balancing the positive charges of metal ions (3d or $4 \mathrm{f}$ ), each oxygen atom of $\mathrm{CO}_{3}{ }^{2-}$ anion in the clusters may act as a monodentate, bifunctional, or trifunctional ligand to generate carbonato-bridged com- 
plexes. ${ }^{11}$ The $\mathrm{CO}_{3}{ }^{2-}$ anion affords various coordination modes, ranging from simple chelation to more intricate coordination modes $\left(\mu_{3}, \mu_{4}, \mu_{5}\right.$ and $\left.\mu_{6}\right)$ to construct complicated metal-carbonate cores. $^{12}$ Therefore, polycarbonate-lanthanoid cores with diverse structures are highly appropriate to construct special RE compounds with 3D open framework topologies. ${ }^{13}$ The $\mathrm{CO}_{3}{ }^{2-}$ anion may also act as a SDA in the design of RE compounds with unique structures, since the $\mathrm{CO}_{3}{ }^{2-}$ anion in the carbonates can be easily removed by calcinations.

Herein we present a series of novel rare earth carbonates $\mathrm{RE}_{3}(\mathrm{OH})_{6}\left(\mathrm{CO}_{3}\right) \mathrm{Cl}(\mathrm{RE}=\mathrm{Dy}, \mathbf{1} ; \mathrm{Er}, 2 ; \mathrm{Y}, 3)$ that exhibit the sodalite-like structure constructed from the building unit (BU) of $\left[\mathrm{RE}_{4}\left(\mu_{3}-\mathrm{OH}\right)_{4}\right]$ cubes by introducing an appropriate amount of $\mathrm{CO}_{3}{ }^{2-}$ from $\mathrm{Na}_{2} \mathrm{CO}_{3}$ or atmospheric carbon dioxide. Remarkably, the calcination of $\mathbf{1}$ at $370{ }^{\circ} \mathrm{C}$ leads to the transformation of $\mathrm{Dy}_{3}(\mathrm{OH})_{6}\left(\mathrm{CO}_{3}\right) \mathrm{Cl}$ to a new open framework compound, $\mathrm{Dy}_{3} \mathrm{O}_{4} \mathrm{Cl}$ (denoted as 1-c). The structures were solved using single-crystal $\mathrm{X}$-ray diffraction. By diluting 1, 1-c and 2 with $\mathrm{Y}$ atoms, the interesting dynamic magnetism of three samples (denoted as 1d $\left(\mathrm{Dy}_{0.0068} \mathrm{Y}_{2.9932}(\mathrm{OH})_{6}\left(\mathrm{CO}_{3}\right) \mathrm{Cl}\right)$, 1d-c $\left(\mathrm{Dy}_{0.0068} \mathrm{Y}_{2.9932} \mathrm{O}_{4} \mathrm{Cl}\right)$ and 2d $\left.\left(\mathrm{Er}_{0.19} \mathrm{Y}_{2.81}(\mathrm{OH})_{6}\left(\mathrm{CO}_{3}\right) \mathrm{Cl}\right)\right)$ have been studied.

\section{Results and discussion}

\section{Syntheses}

Compounds 1, 2 and 3 were prepared by the hydrothermal reaction of a mixture of $\mathrm{RECl}_{3} \cdot 6 \mathrm{H}_{2} \mathrm{O}, 2.5 \mathrm{M} \mathrm{NaOH}, \mathrm{HCl}(37 \mathrm{wt} \%$ ) and $\mathrm{H}_{2} \mathrm{O}$ to get a $\mathrm{pH}$ value of 6 . Finally, $\mathrm{Na}_{2} \mathrm{CO}_{3}$ was introduced to make a reaction gel of $1.0 \mathrm{RECl}_{3}: 1.2 \mathrm{HCl}: 2.5 \mathrm{NaOH}$ : $0.33 \mathrm{Na}_{2} \mathrm{CO}_{3}: 332 \mathrm{H}_{2} \mathrm{O}$. The gel was added into a $12 \mathrm{~mL}$ Teflonlined stainless steel autoclave and reacted at $200{ }^{\circ} \mathrm{C}$ for $72 \mathrm{~h}$. Many parameters including the $\mathrm{pH}$ value and reaction temperature were found to affect the formation of $\mathrm{RE}_{3}(\mathrm{OH})_{6}\left(\mathrm{CO}_{3}\right) \mathrm{Cl}$. The mixture of $\mathrm{HCl}$ and $\mathrm{NaOH}$ was used to reach $\mathrm{pH}=6$ and provide excessive chloride that is beneficial for a high yield. Notably, the addition of $\mathrm{Na}_{2} \mathrm{CO}_{3}$ is essential for the formation of the product. It has been previously shown that the structures of RE clusters and cages are able to be modified by incorporating $\mathrm{CO}_{3}{ }^{2-}$ anions as a template, which is critical for the further aggregation and growth of the product. ${ }^{14}$ In this system, the reaction without $\mathrm{Na}_{2} \mathrm{CO}_{3}$ leads to another RE compound with a $2 \mathrm{D}$ structure, $\mathrm{RE}(\mathrm{OH})_{2} \mathrm{Cl}$, as well as a few target crystals. It suggests that the $\mathrm{CO}_{3}{ }^{2-}$ anion is necessary to generate the $3 \mathrm{D}$ structure in this reaction, and it may be introduced from atmospheric carbon dioxide. Contrarily, if $\mathrm{Na}_{2} \mathrm{CO}_{3}$ is added in a quantity greater than the stoichiometric ratio of 0.33, another known $\mathrm{RE}$ compound $\mathrm{RE}(\mathrm{OH}) \mathrm{CO}_{3}$ is obtained, and the yield of this by-product increases. By further increasing the ratio of $\mathrm{Na}_{2} \mathrm{CO}_{3}$ to 1 , the pure phase of the by-product can be produced. Hence the presence of an appropriate amount of $\mathrm{CO}_{3}{ }^{2-}$ is vital for the syntheses of $\mathbf{1 , 2}$ and 3.

\section{Crystal structures}

Single-crystal structure analyses reveal that 1, 2 and 3 crystallize in the cubic space group $\operatorname{Im} \overline{3}, \operatorname{Im} \overline{3} m$ and $\operatorname{Im} \overline{3} m$, respectively
(Tables S1-S3, ESI $\dagger$ ). The asymmetric unit for each compound contains 0.5 crystallographically distinct RE sites and 0.16667 crystallographically distinct $\mathrm{C}$ sites (Fig. S1, ESI $\dagger$ ). Every RE atom is coordinated with six $\mu_{3}-\mathrm{O}(\mathrm{O}(2)$ and $\mathrm{O}(3))$ atoms from $\mathrm{OH}^{-}$in the framework and four $\mathrm{O}(\mathrm{O}(1))$ atoms from two $\mu_{6}$ $\mathrm{CO}_{3}{ }^{2-}$. Notably, the occupancy of each $\mathrm{O}(1)$ atom is half, due to the disorder of $\mathrm{CO}_{3}{ }^{2-}$. Thus, the $\mathrm{RE}$ atoms are eight-coordinated. The bond distances of $\mathrm{Dy}-\mathrm{O}_{\mu_{3}}$ in 1 vary from 2.302(11) $\AA$ to 2.347 (7) $\AA$, those of $\mathrm{Er}-\mathrm{O}_{\mu_{3}}$ in 2 vary from 2.290(13) $\AA$ to $2.328(8) \AA$ and those of $\mathrm{Y}-\mathrm{O}_{\mu_{3}}$ in 3 vary from $2.333(10) \AA$ to 2.379(6) A (Table S4, ESI $\dagger$ ). The RE-O(1) bond is longer, with an average value of $2.538 \AA$ for $\mathrm{Dy}-\mathrm{O}(1), 2.522 \AA$ for $\mathrm{Er}-\mathrm{O}(1)$ and $2.565 \AA$ for $\mathrm{Y}-\mathrm{O}(1)$. The structure and purity of samples are verified using PXRD experiments (Fig. S2 $\dagger$ ).

1, 2 and $\mathbf{3}$ contain the same structure. Take $\mathbf{1}$ for example, it consists of a $\mathrm{Dy}_{3}(\mathrm{OH})_{6}{ }^{3+}$ cationic framework, with $\mathrm{CO}_{3}{ }^{2-}$ anions located in the centre of the 6-ring opening and $\mathrm{Cl}^{-}$ anions in the channels to achieve charge balance (Fig. 1a). As shown in Fig. 1b, the Dy atoms are linked with each other via six $\mu_{3}-\mathrm{OH}^{-}$, and each Dy atom belongs to two $\left[\mathrm{Dy}_{4}(\mathrm{OH})_{4}\right]$ units. The $\left[\mathrm{Dy}_{4}(\mathrm{OH})_{4}\right]$ unit is the only $\mathrm{BU}$ of the framework. In the centre of the 6-ring opening, a $\mu_{6}-\mathrm{CO}_{3}{ }^{2-}$ ligand binds the six dysprosium ions via a $\mu_{6}-\eta^{2}: \eta^{2}: \eta^{2}$ bridging mode, by coordinating every $\mathrm{O}$ atom of $\mathrm{CO}_{3}{ }^{2-}$ to two Dy atoms on the 6-ring. This coordination mode of $\mathrm{CO}_{3}{ }^{2-}$ is common in clusters. ${ }^{12 d}$ Because of the high symmetry of the structure, the $\mathrm{O}$ atoms here are disordered in two places, each one having an occupancy of one half. The six BUs on the 6-ring opening are linked with each other by vertex-sharing and they form a geo-
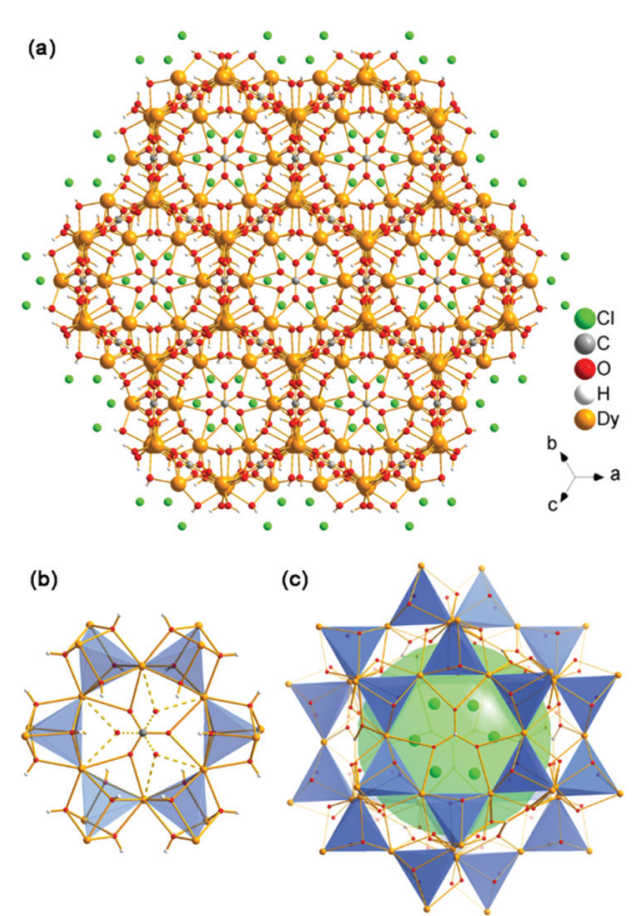

Fig. 1 (a) 3D structure of 1 viewing along the [111] direction; (b) the 6ring opening which templated by $\mathrm{CO}_{3}{ }^{2-}$ anions; (c) the SOD-like cage of the structure. 


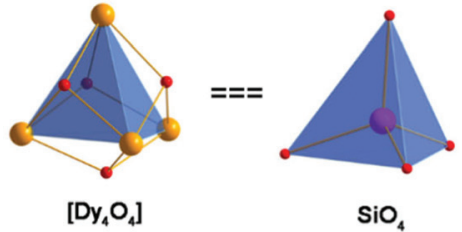

(a)

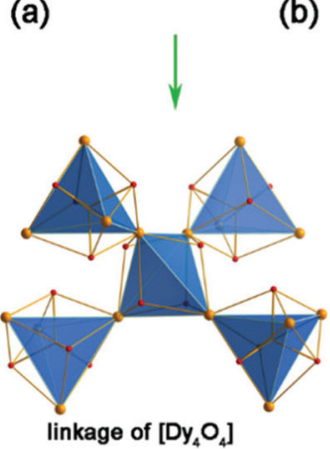

(c)

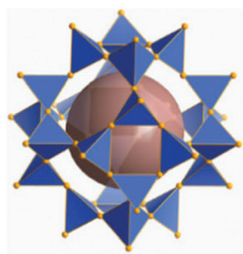

(d)

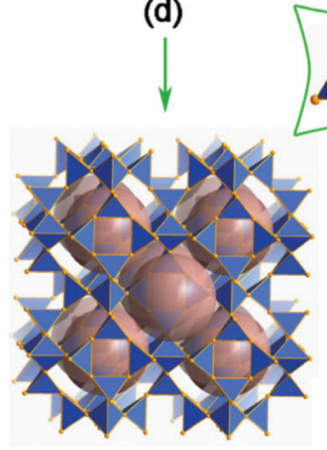

(e)

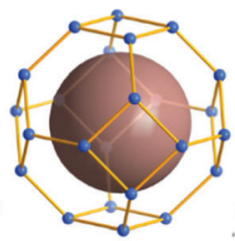

(f)

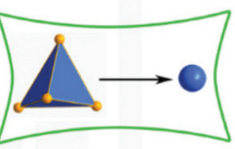

SOD topology

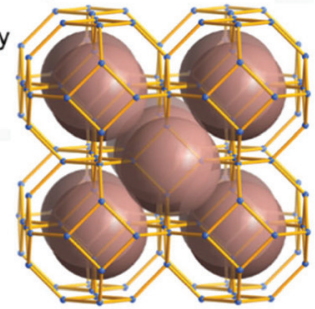

(g)

Fig. 2 (a) The building unit (BU) for the 3D framework of 1, $\left[\mathrm{Dy}_{4} \mathrm{O}_{4}\right]$; (b) the $\mathrm{BU}$ for most zeolites, [SiO 4 ; $(\mathrm{c})$ the linkage of $\left[\mathrm{Dy}{ }_{4} \mathrm{O}_{4}\right] \mathrm{BUs}$ in the 3D framework of 1; (d) the SOD cage linked by $24\left[\mathrm{Dy}_{4}\right]$ tetrahedral nodes; (e) the 3D framework of 1 connected by sharing 6-ring and 4-ring faces from the SOD cages; $(\mathrm{f})$ the SOD cage derived from taking the $\left[\mathrm{Dy}_{4}\right]$ tetrahedron as one tetrahedral node; $(\mathrm{g})$ the SOD topology derived from the structure shown in (e).

metry similar to that of $\left\{\mathrm{Ni}_{12}\right\}$ or $\left\{\mathrm{Mn}_{12}\right\}$ clusters, which are also templated by $\mathrm{CO}_{3}{ }^{2-}$ anions. ${ }^{15}$

Furthermore, an SOD cage can be observed through the vertex-sharing of 24 BUs (Fig. 1c). The cage shows six 4-ring openings and eight 6-ring openings, which are composed by four BUs and six BUs, respectively. Each 6-ring opening is sealed by a $\mathrm{CO}_{3}{ }^{2-}$ anion. $\mathrm{Cl}^{-}$anions in the cages act as the template here, which is similar to the role of alkali metals or organic amines in traditional zeolites. Interestingly, the structure of the super cage is the same as a 60-metalatom cluster, $\left[\mathrm{Er}_{60}(\mathrm{~L}-\mathrm{thre})_{34}\left(\mu_{6}-\mathrm{CO}_{3}\right)_{8}\left(\mu_{3}-\mathrm{OH}\right)_{96}\left(\mu_{2}-\mathrm{O}\right)_{2}\left(\mathrm{H}_{2} \mathrm{O}\right)_{18}\right]$ $\mathrm{Br}_{12}\left(\mathrm{ClO}_{4}\right)_{18}\left(\mathrm{H}_{2} \mathrm{O}\right)_{40}$ (L-thre = $\mathrm{L}$-threonine), that also possesses a sodalite cage structure featuring 24 vertex-sharing $\left[\operatorname{Er}_{4}\left(\mu_{3}-\right.\right.$ $\mathrm{OH})_{4}$ ] cubes. ${ }^{16}$ The cores of the 60 -metal-atom clusters, as well as the $\left\{\mathrm{Ni}_{12}\right\}$ or $\left\{\mathrm{Mn}_{12}\right\}$ clusters, are encapsulated in a coordination sphere, making them independent. But in this framework, the cages combine with each other to give rise to a 3D structure. In general, the anions, such as $\mathrm{CO}_{3}{ }^{2-}$ and $\mathrm{Cl}^{-}$, may have a significant function in directing the structure of rare earth complexes. Besides, the triangular coordination geometry of $\mathrm{CO}_{3}{ }^{2-}$ may induce competing magnetic interactions between the metal centres, such as geometrical spin frustration, which is believed to be beneficial for enhancing magnetocaloric effects. ${ }^{17}$

The $\mathrm{Dy}_{3}(\mathrm{OH})_{6}{ }^{3+}$ open-framework structure of $\mathbf{1}$ is built up from $\mathrm{DyO}_{6}$ polyhedra. This framework features a characteristic body-centred building unit (BU), a $\left[\mathrm{Dy}_{4} \mathrm{O}_{4}\right]$ cube, as shown in Fig. 2a. Each BU is composed of four Dy and four $\mathrm{O}$ atoms alternately connected. The Dy atoms are located on the vertices to form a $\left[\mathrm{Dy}_{4}\right]$ tetrahedron. The $\left[\mathrm{Dy}_{4} \mathrm{O}_{4}\right]$ cube turns out to be a $\left[\mathrm{Dy}_{4}\right]$ tetrahedral node, like the $\mathrm{SiO}_{4}$ or $\mathrm{AlO}_{4}$ tetrahedron as the secondary building unit (SBU) in the zeolite (Fig. 2b). The $\left[\mathrm{Dy}_{4}\right]$ tetrahedra are linked with each other by the vertices (Fig. 2c).

To simplify the structure, all of the $\mathrm{O}_{\mu_{3}}$ atoms are omitted, as shown in Fig. $2 d-g$. Firstly, the $\left[\mathrm{Dy}_{4}\right]$ tetrahedra are linked with each other to give rise to a super cage, which contains 24 $\left[\mathrm{Dy}_{4}\right]$ tetrahedra (Fig. 2d). Through the face-sharing of the SOD-like cages, a 3D open framework of 1 (Fig. 2e) is constructed, which contains 3D intersection channels along the [111], [11̄1], [11ī] and [i111] directions. Considering the [Dy tetrahedron as a tetrahedral node, the cage is built up through the vertex-sharing of the $\left[\mathrm{Dy}_{4}\right]$ tetrahedra, which is very similar to the typical sodlite cage (Fig. 2f). The framework of $\mathbf{1}$ shows the topology of SOD, as shown in Fig. 2g. The free diameters are $4.1 \times 4.3 \AA^{2}$ (Dy *..Dy distance) for the 6-ring channel, which is comparable to those of 8-ring channels in aluminosilicate zeolites, such as CHA, LEV, LTA, etc. The framework density (FD) of $\mathbf{1}$ is 12.3 Dy atoms per $1000 \AA^{3}$. That is lower than SOD with $\mathrm{FD}_{\mathrm{Si}}$ of $16.7 \mathrm{~T} / 1000 \AA^{3}$ and comparable to some zeolites with 8-ring channels due to the long distance of the Dy-O bond. ${ }^{18}$ The SOD topology was firstly discovered for the mineral sodalite in 1930, and used to be studied in zeolites. ${ }^{19}$ Recently, the SOD topology has also been exhibited in several ZMOFs or ZIFs. ${ }^{20}$ This is one of the rare examples of a rare earth complex with a zeolite topology. ${ }^{21}$ It may act as a guidance to explore new RE compounds with zeolite topology by using a $\left[\mathrm{RE}_{4}\right]$ tetrahedron as building unit.

The framework of $\mathbf{1}$ can be described as a three-period net with the highest symmetry of $\operatorname{Im} \overline{3} m$ containing only one type of $\mathrm{T}$ site as determined by the Systre software. ${ }^{22}$ The vertex symbol for the $\mathrm{T}$ site in the net is $3_{6} \cdot 4 \cdot 5_{4} \cdot 6_{4}$. This three-period 
net features a unique natural tiling with a transitivity of $\left(\begin{array}{lll}1 & 2 & 3\end{array}\right.$ $2)$. There are two different tiles in this tiling with face symbols of $\left[3^{4}\right]$ and $\left[3^{24} \cdot 4^{6} \cdot 6^{8}\right]$. The signature of this tiling is $6\left[3^{4}\right]+$ $\left[3^{24} \cdot 4^{6} \cdot 6^{8}\right]$. Considering the building unit of $\left[\mathrm{Dy}_{4}(\mathrm{O})_{4}\right]$, the framework of 1 also can be described as a three-period net of SOD topology with the highest symmetry of $\operatorname{Im} \overline{3} m$. The vertex symbol for the $\mathrm{T}$ site in the net is $4_{2} \cdot 6_{4}$. This three-period net is carried by a unique natural tiling with a transitivity of

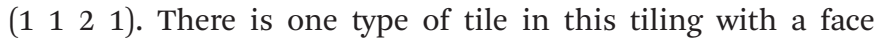
symbol of $\left[4^{6} \cdot 6^{8}\right]$.

TG analysis has been performed to study the thermal stability of 1. It shows a total weight loss of $18.6 \%$ from 200 to $800{ }^{\circ} \mathrm{C}$ with two stages with the first one occurring between $300-450{ }^{\circ} \mathrm{C}$ (Fig. S3†). Under heat treatment at $370{ }^{\circ} \mathrm{C}$ for $4 \mathrm{~h}$, the structure will transform into 1-c. Surprisingly, the structure of 1-c can be solved using single-crystal X-ray diffraction. This phenomenon is rarely observed in RE inorganic compounds. In the analysis of the single-crystal X-ray diffraction data, we noticed that the $\mathrm{CO}_{3}{ }^{2-}$ anions are removed. The space group has transformed into trigonal $R \overline{3}$ for 1-c from cubic $\operatorname{Im} \overline{3}$ for $\mathbf{1}$. Besides, some micro variation occurs in the structure. Here, we consider the $\mathrm{CO}_{3}{ }^{2-}$ anions are removed by forming $\mathrm{CO}_{2}$ during the calcinations. From the TG curve, the first stage weight loss of $13.6 \mathrm{wt} \%$ occurs at around $370{ }^{\circ} \mathrm{C}$, which corresponds with the removal of $\mathrm{CO}_{2}$ and $\mathrm{H}_{2} \mathrm{O}$. The complex then has a molecular formula of $\mathrm{Dy}_{3} \mathrm{O}_{4} \mathrm{Cl}$. The possible chemical equation is shown as follows:

$$
\mathrm{Dy}_{3}(\mathrm{OH})_{6}\left(\mathrm{CO}_{3}\right) \mathrm{Cl} \rightarrow \mathrm{Dy}_{3} \mathrm{O}_{4} \mathrm{Cl}+\mathrm{CO}_{2}+3 \mathrm{H}_{2} \mathrm{O}
$$

The PXRD pattern of 1-c corresponds well with the simulated one based on the single-crystal structure of 1-c, indicating the pure phases of the as-synthesized sample (Fig. S4†). The formula of 1-c is confirmed by ICP, elemental analyses and anion chromatography analysis (Dy, 82.7; C, 0.41; H, 0.92; Cl, 5.95; Anal. Calcd Dy, 83.0; C, 0; H, 0; Cl, 6.04 wt\%). In addition, X-ray photoelectron spectroscopy (XPS) of 1 and 1-c are also measured to verify the existence of Cl. Fig. S5† shows the XPS survey spectra and narrow scan XPS spectra of 1 and 1-c. The signal at around $198 \mathrm{eV}$ is consistent with the binding energy of $\mathrm{Cl} 2 \mathrm{p}$, indicating the existence of $\mathrm{Cl}^{-}$in the structures. $^{23}$ The content ratios of $\mathrm{Dy} / \mathrm{Cl}$ for $\mathbf{1}$ and 1-c derived from the XPS analysis are close to 3, corresponding to the formula of $\mathrm{Dy}_{3}(\mathrm{OH})_{6}\left(\mathrm{CO}_{3}\right) \mathrm{Cl}$ and $\mathrm{Dy}_{3} \mathrm{O}_{4} \mathrm{Cl}$, respectively. Additionally, the calcination derivatives (2-c and 3-c) with similar structures can be obtained following the same treatment for 2 , and 3 .

Single-crystal structure analysis of 1-c reveals that the asymmetric unit contains three crystallographically distinct Dy sites and four crystallographically distinct O sites (Fig. S6, ESI $\dagger$ ). Dy(1) and Dy(2) are six-coordinated with six $\mu_{4}-\mathrm{O}(\mathrm{O}(1), \mathrm{O}(2)$, $\mathrm{O}(3)$ and $\mathrm{O}(4))$, Dy(3) is seven-coordinated with four $\mu_{4}-\mathrm{O}$ and three $\mathrm{Cl}$ atoms. The $\mathrm{Dy}-\mathrm{O}_{\mu_{4}}$ bond lengths have a reasonable range of 2.13(4)-2.41(6) $\AA$.

The structure of 1-c may be described as a cationic framework of $\mathrm{Dy}_{3} \mathrm{O}_{4}{ }^{+}$units with 3D intersection 6-ring channels along the [001], [111], [211] and [121] directions (Fig. 3a and $\mathrm{S} 7 \dagger) \mathrm{Cl}^{-}$anions are situated in the channels to balance the
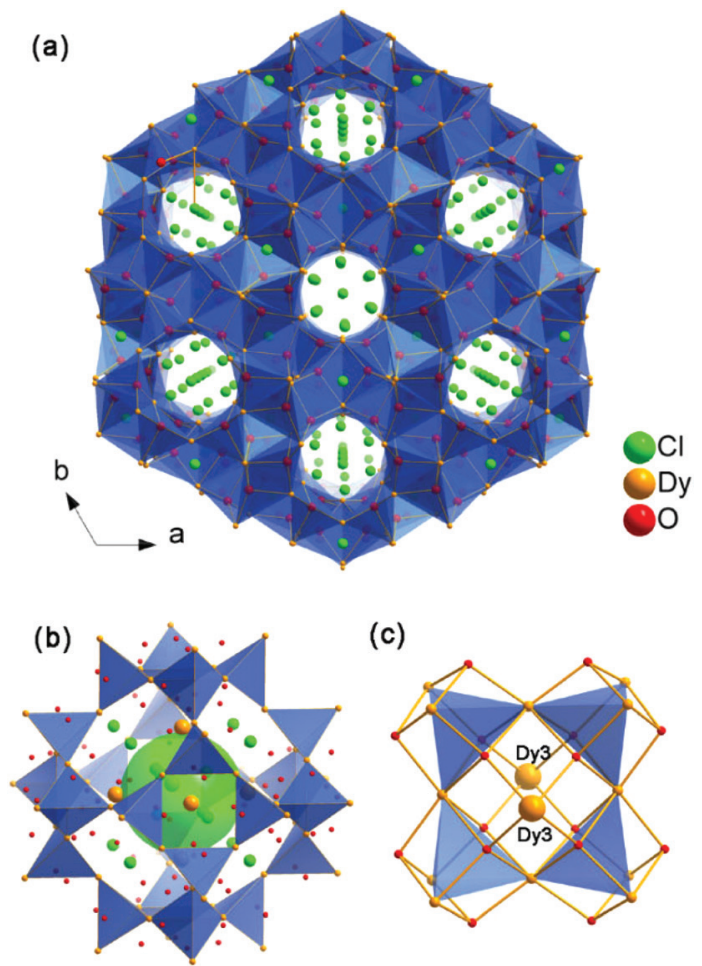

(c)

(d)

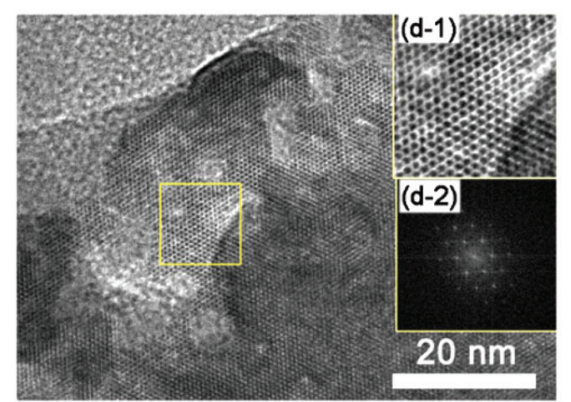

Fig. 3 (a) Structure of 1-c viewed along the [001] direction; (b) super cage linked by $24\left[\mathrm{Dy}_{4}\right]$ tetrahedra; (c) the coordination between $\mathrm{Dy}(3)$ atoms and the 4-ring opening of the super cage; (d) HRTEM micrograph of 1-c along the [010] zone axis. Inset: (d-1) enlarged image of the yellow box and corresponding FFT; (d-2) enlarged zones of the crystallographic

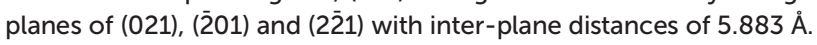

charge. Compared with $\mathbf{1}$, all of the $\mathrm{CO}_{3}{ }^{2-}$ anions have been removed. The 3D open framework of 1-c is constructed by facesharing of the super cages, which is similar to $\mathbf{1}$, as shown in Fig. 3 b. However, all of the $\mu_{3}-\mathrm{OH}$ in 1 have become $\mu_{4}-\mathrm{O}$ in 1-c. The $\mu_{4}-\mathrm{O}$ connect to one $\mathrm{Dy}(3)$ atom and three other Dy atoms (Dy(1) and/or Dy(2)) to form anion-centered ODy ${ }_{4}$ tetrahedra, which is common in inorganic compounds. ${ }^{24}$ By ignoring the Dy(3) atom, the framework of 1-c also contains vertexsharing linkage of the $\left[\mathrm{Dy}_{4}\right]$ cubes with the same framework of 1. In the SOD-like cage, the $\left[\mathrm{Dy}_{4}\right]$ cubes are comprised of all of the Dy(1) and Dy(2) atoms with Dy(3) situated nearby the six 4-ring openings. Inside and outside the 4-ring opening, there is a central $\mathrm{Dy}(3)$ atom that links to the four $\left[\mathrm{Dy}_{4} \mathrm{O}_{4}\right]$ cubes by coordinating with four $\mathrm{O}$ atoms from the four cubes (Fig. 3c). 
As shown in Fig. 3d, the high-resolution TEM images (HRTEM) of 1-c clearly show a hexagonal lattice with void distances of $5.9 \AA$, which corresponds to the distances of the crys-

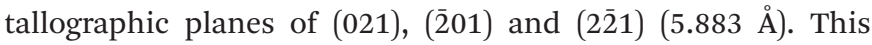
further confirms the structure of 1-c.

\section{Magnetic analyses}

Dc magnetic susceptibility data of 1, 1-c and the corresponding diluted samples (1d and 1d-c, respectively) are measured in the temperature range of $2-300 \mathrm{~K}$ (Fig. 4). At $300 \mathrm{~K}$, the $\chi_{\mathrm{m}} T$ products for the samples are 13.90, 13.81, 13.29 and $13.39 \mathrm{~cm}^{3} \mathrm{~K} \mathrm{~mol}^{-1}$ for $\mathbf{1}, \mathbf{1 d}, \mathbf{1 - c}$ and 1d-c, respectively, which are compatible with the calculated value of $14.17 \mathrm{~cm}^{3} \mathrm{~K}$ $\mathrm{mol}^{-1}$ for the ground state of one Dy ${ }^{\mathrm{III}}$ ion $\left(4 \mathrm{f}^{9}, S=5 / 2, L=5\right.$, $J=15 / 2$ and $g=4 / 3$ ) in the free ion approximation. Upon cooling, the $\chi_{\mathrm{m}} T$ products decrease gradually at first and then more rapidly to the minimum at $2 \mathrm{~K}$ for all of the compounds.

The $\chi_{\mathrm{m}} T$ versus $T$ plots for compounds $\mathbf{2}$ and $\mathbf{2 d}$ are recorded between 2 and $300 \mathrm{~K}$ under a dc field of 500 Oe and 1 kOe, respectively (Fig. 4). The $\chi_{\mathrm{m}} T$ values at room temperature are 10.87 and 10.80 for 2 and $\mathbf{2 d}$, respectively, which are close to the expected value of $11.48 \mathrm{~cm}^{3} \mathrm{~K} \mathrm{~mol}^{-1}$ for one $\mathrm{Er}^{\mathrm{III}}$ ion $\left(4 \mathrm{f}^{12}, S=3 / 2, L=6, J=15 / 2\right.$ and $\left.g=6 / 5\right)$. In the high-temperature range, the $\chi_{\mathrm{m}} T$ product decreases slowly upon cooling for both compounds; below $75 \mathrm{~K}$, the $\chi_{\mathrm{m}} T$ product drops quickly to a minimum value of $3.74 \mathrm{~cm}^{3} \mathrm{~K} \mathrm{~mol}^{-1}$ at $2 \mathrm{~K}$ for 2 , and a minimum value of $6.17 \mathrm{~cm}^{3} \mathrm{~K} \mathrm{~mol}^{-1}$ for the diluted sample of $2 d$.

The magnetization versus field plots are determined at low temperatures in the range of $0-70 \mathrm{kOe}$, as shown in Fig. S8. $\dagger$ For 1 and 1-c, the magnetization at $2 \mathrm{~K}$ increases continuously upon an increase of the magnetic field, reaching the maxima of $5.57 N_{\beta}$ and $5.04 N_{\beta}$ for 1 and 1-c, respectively. These obtained values are far from the saturated magnetization for one Dy ${ }^{\mathrm{III}}$ ion, but are in agreement with the data reported pre-

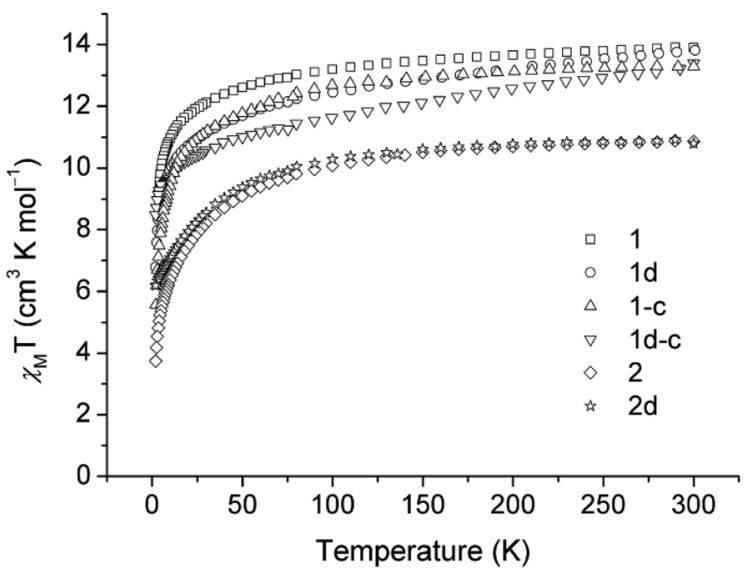

Fig. 4 Experimental $\chi_{\mathrm{m}} T$ products of $1,1 \mathrm{~d}, 1-\mathrm{c}, 1 \mathrm{~d}-\mathrm{c}, 2$ and $2 \mathrm{~d}$ in an applied field of $2 \mathrm{kOe}, 1 \mathrm{kOe}, 1 \mathrm{kOe}, 1 \mathrm{kOe}, 0.5 \mathrm{KOe}$ and $1 \mathrm{kOe}$ for 1, 1d, $1-c, 1 d-c, 2$ and $2 d$, respectively. The $\chi_{m} T$ curve has been rescaled for one $\mathrm{RE}^{\mathrm{II}}$ ion. viously as a result of the large magneto-anisotropy and/or the low lying excited states of the Dy ${ }^{\text {III }}$ ion. For 2, similar behavior of the field-dependent magnetization is observed, with a highest value of $4.46 N_{\beta}$ at $2 \mathrm{~K}$, which again does not exhibit saturation, possibly due to the presence of large magnetic anisotropy.

Alternating current (ac) susceptibility measurements were performed on the microcrystalline samples to investigate the dynamic behaviour of the magnetization at low temperatures, as displayed in Fig. S9. $\dagger$ For 1, 1-c and 2, curves based on the in-phase and out-of-phase signals of the ac susceptibility are all superimposed on a nearly single-master curve, either in the absence of an external dc field or at an applied dc field of 1 kOe. This phenomenon often exists in high-nuclearity lanthanide cages, and is probably due to the crowded distribution of metal ions in high-nuclearity clusters, as well as in titled complexes. $^{25}$

Magnetic dilution may enhance the slow magnetic relaxation $U_{\text {eff }}$ originating from SIM behaviour in mononuclear and polymeric compounds, such as $1 \mathrm{D}$ dysprosium chains, 2D layers, and even $3 \mathrm{D} \mathrm{LiYF}_{4}$ compounds. ${ }^{26}$ It is an advantage here that we can study the magnetism of samples with very large dilution ratios of up to $0.227 \%$, for which the magnetic signal is still precluded by the instrument sensitivity for $\mathbf{1}$ and 1-c, while the same cannot be detected for most diluted samples reported. Therefore, the doped samples 1d and 1d-c in Dy: $\mathrm{Y}$ molar ratios of 1:440 are prepared to examine the nature of the magnetism. As shown in Fig. 5, ac measurements for both diluted samples in zero dc field show obvious frequency dependence below $8 \mathrm{~K}$, an indication of slow relaxation of the magnetization. Unfortunately, no maximum is observed in both the in-phase and out-of-phase signals of the ac susceptibility, possibly due to the presence of a fast relaxation of the magnetisation through a quantum tunnelling mechanism. Thus, ac measurements are taken under an applied small external dc field of 500 Oe to mitigate the quantum tunnelling (Fig. S10†). Significant frequency-dependent $\chi^{\prime}$ and $\chi^{\prime \prime}$ signals
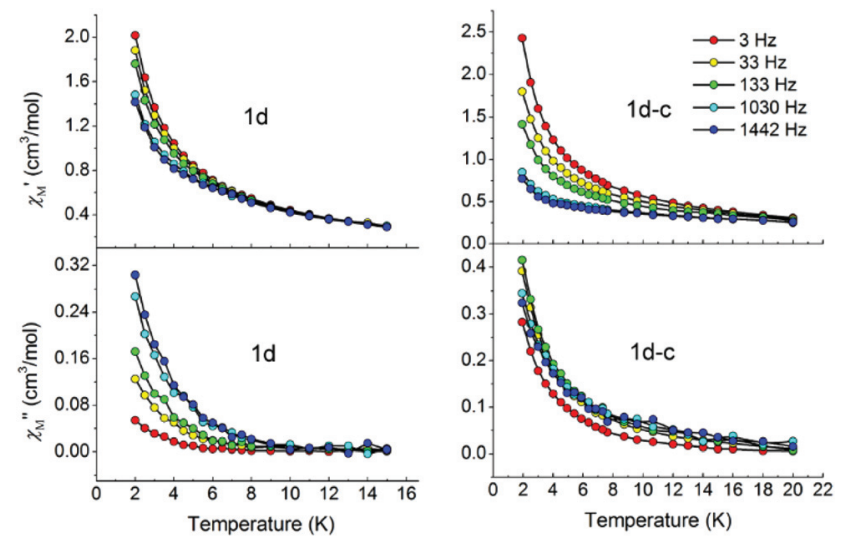

Fig. 5 In-phase (top) and out-of-phase (bottom) dynamic susceptibilities of $1 \mathrm{~d}$ and $1 \mathrm{~d}-\mathrm{c}$ without external dc magnetic fields. Solid lines are included to guide the eyes. 
appear for both compounds and a maximum in $\chi^{\prime}$ is clearly observed moving to higher temperatures towards higher frequencies especially for $\mathbf{1 d}$, indicating SIM behaviour.

For 2, a similar phenomenon has occurred (Fig. S11†). The doped sample $2 \mathrm{~d}$ with a Dy: Y molar ratio of $1: 15$ shows slow relaxation of its magnetization under a dc field of 1 kOe, proving the position effect that the dilution of open framework materials has on the SIM behaviour once again. All the information points out that such a slow relaxation is likely dominated by single ion effects, and vanishes when more of the lanthanide ions are incorporated. The magnetic exchange interaction, although it is weak between lanthanides, and the dipolar interaction, as well as the orientation of the easy axes of magnetization work together in the molecular architecture, leading to a complicated situation which is not beneficial to the SIM behaviour.

\section{Conclusions}

In conclusion, we have successfully synthesized a series of novel rare earth carbonates $\mathrm{RE}_{3}(\mathrm{OH})_{6}\left(\mathrm{CO}_{3}\right) \mathrm{Cl}(\mathrm{RE}=$ Dy (1), Er (2), Y (3)) with SOD-like structures built from $\left[\mathrm{RE}_{4}\left(\mu_{3}-\mathrm{OH}\right)_{4}\right]$ cubes by introducing $\mathrm{CO}_{3}{ }^{2-}$ for the first time. Interestingly, the $\mathrm{CO}_{3}{ }^{2-}$ can be the removed after calcination at $370{ }^{\circ} \mathrm{C}$. In addition, the single-crystal of 1 can be in situ transformed into a new zeolitic compound $\mathrm{Dy}_{3} \mathrm{O}_{4} \mathrm{Cl}$ (1-c) with two Dy atoms located at both sides of the 4-ring on the SOD-like structure. Magnetic studies of both diluted samples of 1 and 1-c show that they exhibit SIM-type behaviours. As such, both diluted compounds can be safely labelled as $\mathrm{M}^{0} \mathrm{U}^{0} \mathrm{~S}^{3}$ according to their magneto-structural correlations. ${ }^{27}$ These results provide guidance on the syntheses of RE-based open frameworks, and promisingly open a new door towards diluted magnets.

\section{Experimental section}

Reagents and solvents were commercially available and used as received without further purification.

\section{Synthetic procedures}

Synthesis of $\mathrm{Dy}_{3}(\mathrm{OH})_{6}\left(\mathrm{CO}_{3}\right) \mathrm{Cl}$ (1). Typically, dysprosium(III) chloride hexahydrate $\left(\mathrm{DyCl}_{3} \cdot 6 \mathrm{H}_{2} \mathrm{O}, 1 \mathrm{mmol}\right)$ was dispersed into $5 \mathrm{~mL}$ distilled water, and fully dissolved by adding $0.1 \mathrm{~mL}$ hydrochloric acid (37 wt\%, $1.2 \mathrm{mmol})$. Then $1 \mathrm{~mL} \mathrm{NaOH}$ solution $\left(2.5 \mathrm{~mol} \mathrm{~L}^{-1}\right)$ was added to the mixture with stirring for $1 \mathrm{~h}$ to get a $\mathrm{pH}$ value of 6 . Finally, $\mathrm{Na}_{2} \mathrm{CO}_{3}$ was introduced to make a reaction gel of $1.0 \mathrm{DyCl}_{3}: 1.2 \mathrm{HCl}: 2.5 \mathrm{NaOH}: 0.33$ $\mathrm{Na}_{2} \mathrm{CO}_{3}: 332 \mathrm{H}_{2} \mathrm{O}$. About $1 \mathrm{~h}$ later, the gel was added into a $12 \mathrm{~mL}$ Teflon-lined stainless steel autoclave and heated at $200{ }^{\circ} \mathrm{C}$ for $72 \mathrm{~h}$, followed by cooling to room temperature for $20 \mathrm{~h}$. The white pure crystals were obtained by washing in distilled water several times and dried at room temperature overnight after filtration. Yield: $176 \mathrm{mg}$ (77\% based on Dy). Elemental analysis of the product gave (in wt\%) Dy: 70.9
(Calcd Dy: 71.2), C: 1.84 (Calcd C: 1.75), H: 1.21 (Calcd H: 0.876 ), and anion chromatography analysis gave (in $\mathrm{wt} \%$ ) $\mathrm{Cl}$ : 5.11 (Calcd Cl: 5.18), which were consistent with the elemental content calculated from the molecular formula of $\mathrm{Dy}_{3}(\mathrm{OH})_{6}\left(\mathrm{CO}_{3}\right) \mathrm{Cl}$.

Synthesis of $\mathrm{Er}_{3}(\mathrm{OH})_{6}\left(\mathrm{CO}_{3}\right) \mathrm{Cl}$ (2). Compound 2 was synthesized following a method similar to that of $\mathbf{1}$, using erbium(III) chloride hexahydrate $\left(\mathrm{ErCl}_{3} \cdot 6 \mathrm{H}_{2} \mathrm{O}\right)$ instead of $\mathrm{DyCl}_{3} \cdot 6 \mathrm{H}_{2} \mathrm{O}$ to make a reaction gel of $1.0 \mathrm{ErCl}_{3}: 1.2 \mathrm{HCl}: 2.5 \mathrm{NaOH}: 0.33 \mathrm{Na}_{2} \mathrm{CO}_{3}$ : $332 \mathrm{H}_{2} \mathrm{O}$. The product was obtained with a yield of $53 \%$ based on Er with the molecular formula of $\mathrm{Er}_{3}(\mathrm{OH})_{6}\left(\mathrm{CO}_{3}\right) \mathrm{Cl}$.

Synthesis of $\mathrm{Y}_{3}(\mathrm{OH})_{6}\left(\mathrm{CO}_{3}\right) \mathrm{Cl}$ (3). Compound 3 was synthesized following a method similar to that of $\mathbf{1}$, using yttrium (III) chloride hexahydrate $\left(\mathrm{YCl}_{3} \cdot 6 \mathrm{H}_{2} \mathrm{O}\right)$ instead of $\mathrm{DyCl}_{3} \cdot 6 \mathrm{H}_{2} \mathrm{O}$ to make a reaction gel of $1.0 \mathrm{YCl}_{3}: 1.2 \mathrm{HCl}: 2.5 \mathrm{NaOH}: 0.33 \mathrm{Na}_{2} \mathrm{CO}_{3}$ : $332 \mathrm{H}_{2} \mathrm{O}$. The product was obtained with a yield of $80 \%$ based on $\mathrm{Y}$ with the molecular formula of $\mathrm{Y}_{3}(\mathrm{OH})_{6}\left(\mathrm{CO}_{3}\right) \mathrm{Cl}$.

Synthesis of $\mathrm{Dy}_{0.0068} \mathrm{Y}_{2.9932}(\mathrm{OH})_{6}\left(\mathrm{CO}_{3}\right) \mathrm{Cl}(1 \mathrm{~d}, 0.227 \%$ diluted sample of 1). $\mathrm{DyCl}_{3} \cdot 6 \mathrm{H}_{2} \mathrm{O} / \mathrm{YCl}_{3} \cdot 6 \mathrm{H}_{2} \mathrm{O}$ (in a $1: 449$ molar ratio; $10 \mathrm{mmol}$ in total) was dispersed into $50 \mathrm{~mL}$ water, and $1 \mathrm{~mL}$ hydrochloric acid (37 wt\%, $12 \mathrm{mmol}$ ) was added. Then $10 \mathrm{~mL}$ $\mathrm{NaOH}\left(2.5 \mathrm{~mol} \mathrm{~L}^{-1}\right)$ was added to the mixture with stirring for $1 \mathrm{~h}$ to get a $\mathrm{pH}$ value of 6 . Finally, $\mathrm{Na}_{2} \mathrm{CO}_{3}$ was introduced to make a reaction gel of $0.002 \mathrm{DyCl}_{3}: 0.998 \mathrm{YCl}_{3}: 1.2 \mathrm{HCl}: 2.5$ $\mathrm{NaOH}: 0.33 \mathrm{Na}_{2} \mathrm{CO}_{3}: 332 \mathrm{H}_{2} \mathrm{O}$. About $1 \mathrm{~h}$ later, the gel was added into a $100 \mathrm{~mL}$ Teflon-lined stainless steel autoclave and heated at $200{ }^{\circ} \mathrm{C}$ for $72 \mathrm{~h}$, followed by cooling to room temperature for $20 \mathrm{~h}$. Pure crystals of 1d were obtained after washing the product in distilled water and were dried at room temperature overnight. The Dy/Y ratio of the product based on ICP analysis (in wt\%) Dy: 0.238, Y: 57.2, gave the molecular formula Dy $0.0068 \mathrm{Y}_{2.9932}(\mathrm{OH})_{6}\left(\mathrm{CO}_{3}\right) \mathrm{Cl}$.

Synthesis of $\mathrm{Er}_{0.19} \mathrm{Y}_{2.81}(\mathrm{OH})_{6}\left(\mathrm{CO}_{3}\right) \mathrm{Cl}$ (2d, 6.25\% diluted sample of 2). Compound 2d was synthesized following a method similar to that of $\mathbf{1 d}$, using erbium(III) chloride hexahydrate $\left(\mathrm{ErCl}_{3} \cdot 6 \mathrm{H}_{2} \mathrm{O}\right)$ instead of $0.06 \mathrm{ErCl}_{3}: 0.94 \mathrm{YCl}_{3}: 1.2 \mathrm{HCl}$ : $2.5 \mathrm{NaOH}: 0.33 \mathrm{Na}_{2} \mathrm{CO}_{3}: 332 \mathrm{H}_{2} \mathrm{O}$. The $\mathrm{Er} / \mathrm{Y}$ ratio of the product based on ICP analysis (in wt\%) Er: 6.63, Y: 52.1, gave the molecular formula of $\mathrm{Er}_{0.19} \mathrm{Y}_{2.81}(\mathrm{OH})_{6}\left(\mathrm{CO}_{3}\right) \mathrm{Cl}$.

Preparation of $\mathrm{Dy}_{3} \mathrm{O}_{4} \mathrm{Cl}$ (1-c, the calcined sample from 1). The as-synthesized 1 was placed into a normal furnace and heated from $\mathrm{RT}$ to $370{ }^{\circ} \mathrm{C}$ at a temperature ramp rate of $1^{\circ} \mathrm{C}$ $\min ^{-1}$ in air with a $4 \mathrm{~h}$ isothermal hold at $370{ }^{\circ} \mathrm{C}$ before cooling to room temperature at a rate of $1^{\circ} \mathrm{C} \mathrm{min}^{-1}$. The transformation of the structure occurred during this process. The composition of 1-c is studied by ICP, elemental analyses and anion chromatography analyses (Dy, 82.7; C, 0.41; H, 0.92; Cl, 5.95; Anal. Calcd Dy, 83.0; C, 0; H, 0; Cl, 6.04 wt\%). Singlecrystal analysis show that 1-c exhibits a new structure. Besides, the calcination derivatives (2-c and 3-c) with a similar structure can also be obtained following the same treatment of 2 , and 3 . The structure and purity of the samples are confirmed by PXRD.

Preparation of $\mathrm{Dy}_{0.0068} \mathrm{Y}_{2.9932} \mathrm{O}_{4} \mathrm{Cl}$ (1d-c, $0.227 \%$ diluted sample of 1-c). The as-synthesized 1d was placed into a normal furnace and treated following the method similar to 1-c. The structures of 1d-c are confirmed by PXRD. 


\section{Characterization methods}

PXRD data were collected on a Rigaku SmartLab(3) diffractometer with $\mathrm{Cu} \mathrm{K} \alpha$ radiation $(\lambda=1.5418 \AA$ A $)$. Inductively coupled plasma (ICP) analysis was performed on a PerkinElmer Optima 3300DV spectrometer. Elemental analysis was conducted on a Vario MICRO elemental analyzer. Anion chromatography analysis was performed on a DX-500 Ion Chromatography (IC) System of Dionex. Thermogravimetric analysis (TGA) was carried out on a TA Q500 analyzer in air with a heating rate of $10{ }^{\circ} \mathrm{C} \mathrm{min}^{-1}$ from $\mathrm{RT}$ to $800{ }^{\circ} \mathrm{C}$. X-ray photoelectron spectroscopy (XPS) measurements were performed using a Thermo Escalab 250 spectrometer with monochromatized Al K $\alpha$ excitation. The TEM and HRTEM images were taken on a JEOL JEM-3010 transmission electron microscope operating at an accelerating voltage of $300 \mathrm{kV}$. Magnetic measurements were performed on a Quantum Design MPMS XL-7 SQUID magnetometer on polycrystalline samples. Diamagnetic corrections were made with Pascal's constants for all the constituent atoms and sample holder. Alternating-current (ac) magnetic susceptibility data were collected on the same instrument employing a 3.5 Oe oscillating field at frequencies up to $1442 \mathrm{~Hz}$.

\section{X-ray crystallographic analyses}

Suitable single crystals of $\mathrm{Dy}_{3}(\mathrm{OH})_{6}\left(\mathrm{CO}_{3}\right) \mathrm{Cl}(\mathbf{1}), \mathrm{Er}_{3}(\mathrm{OH})_{6}\left(\mathrm{CO}_{3}\right) \mathrm{Cl}$ (2), $\mathrm{Y}_{3}(\mathrm{OH})_{6}\left(\mathrm{CO}_{3}\right) \mathrm{Cl}(3)$ and $\mathrm{Dy}_{3} \mathrm{O}_{5} \mathrm{Cl}_{0.5} \mathrm{H}_{1.5}$ (1-c) with dimensions of $0.32 \times 0.21 \times 0.15,0.07 \times 0.07 \times 0.05,0.05 \times 0.05 \times 0.05$ and $0.06 \times 0.06 \times 0.03 \mathrm{~mm}^{3}$, respectively, were selected for single-crystal X-ray diffraction analyses. The intensity data were collected on a Bruker Apex II DUO area-detector diffractometer with graphite-monochromated Mo K $\alpha$ radiation $(\lambda=0.71073 \AA)$ at a temperature of $23 \pm 2{ }^{\circ} \mathrm{C}$. Cell refinement and data reduction were accomplished with the SAINT processing program. ${ }^{28}$ The structures were solved by direct methods and refined by a full matrix least-squares technique with the SHELXTL crystallographic software package. ${ }^{29}$ The heaviest atoms of Dy, Er, Y, O, $\mathrm{Cl}$ and $\mathrm{C}$ could be unambiguously located. The $\mathrm{H}$ atoms in the structures of 1,2 and 3 were added theoretically, and that of 1-c were not added. All nonhydrogen atoms were refined anisotropically. CCDC 1416221-1416224 contain the supplementary crystallographic data for this paper. Crystal data and refinement parameters for the structure determination are presented in Tables S1-3 and $\mathrm{S} 5 . \dagger$ Selected bond distances are listed in the Table S4. $\dagger$

\section{Acknowledgements}

Financial support from "973 projects" (2012CB619401 and 2012CB619402), NSFC (21473129, 21201137 and IRT13034), the China Postdoctoral Science Foundation (Grant 2014M562393), the "National 1000-Plan" program, and the Fundamental Research Funds for the Central Universities. We thank the MOF team from Jilin University (Dr Ying Mu, Prof. Jiyang Li and Prof. Jihong Yu) for TEM and elemental analyses.
We thank the team from Xi'an Jiaotong University (Dr Yali Lei and Prof. Zhenxing Shen) for anion chromatography analysis.

\section{Notes and references}

1 (a) A. Corma, Chem. Rev., 1997, 97, 2373-2420; (b) J. Li, A. Corma and J. Yu, Chem. Soc. Rev., 2015, 44, 71127127; (c) Y. Li and J. Yu, Chem. Rev., 2014, 114, 72687316.

2 C. Baerlocher and L. B. McCusker, Database of Zeolite Structures: http://www.iza-structure.org/databases/.

3 (a) G. Yang, Y. Wang, D. Zhou, J. Zhuang, X. Liu, X. Han and X. Bao, J. Chem. Phys., 2003, 119, 9765-9770; (b) N. Rahimi and R. Karimzadeh, Appl. Catal., A, 2011, 398, 1-17; (c) M. Iwasaki and H. Shinjoh, Chem. Commun., 2011, 47, 3966-3968; (d) S. Kim, E. Sasmaz and J. Lauterbach, Appl. Catal., B, 2015, 168-169, 212-219.

4 (a) D. Ananias, F. A. Almeida Paz, L. D. Carlos, C. F. G. C. Geraldes and J. Rocha, Angew. Chem., Int. Ed., 2006, 45, 7938-7942; (b) X. Wang, J. Li, Y. Han, Y. Li, J. Yu and R. Xu, Chem. Mater., 2011, 23, 2842-2847.

5 (a) N. Ishikawa, M. Sugita, T. Ishikawa, S. Koshihara and Y. Kaizu, J. Am. Chem. Soc., 2003, 125, 8694-8695; (b) L. Sorace, C. Benelli and D. Gatteschi, Chem. Soc. Rev., 2011, 40, 3092-3104; (c) Y.-L. Wang, Y. Ma, X. Yang, J. Tang, P. Cheng, Q.-L. Wang, L.-C. Li and D.-Z. Liao, Inorg. Chem., 2013, 52, 7380-7386.

6 (a) M. Mannini, F. Pineider, C. Danieli, F. Totti, L. Sorace, P. Sainctavit, M. A. Arrio, E. Otero, L. Joly, J. C. Cezar, A. Cornia and R. Sessoli, Nature, 2010, 468, 417-421; (b) S. Cardona-Serra, J. M. Clemente-Juan, E. Coronado, A. Gaita-Ariño, A. Camón, M. Evangelisti, F. Luis, M. J. Martínez-Pérez and J. Sesé, J. Am. Chem. Soc., 2012, 134, 14982-14990; (c) D. N. Woodruff, R. E. P. Winpenny and R. A. Layfield, Chem. Rev., 2013, 113, 5110-5148; (d) H. Miyasaka, K. Nakata, K.-i. Sugiura, M. Yamashita and R. Clérac, Angew. Chem., Int. Ed., 2004, 43, 707-711; (e) I.-R. Jeon and R. Clerac, Dalton Trans., 2012, 41, 95699586; $(f)$ J. J. Baldoví, E. Coronado, A. Gaita-Ariño, C. Gamer, M. Giménez-Marqués and G. Mínguez Espallargas, Chem. - Eur. J., 2014, 20, 10695-10702.

7 (a) R. Giraud, W. Wernsdorfer, A. M. Tkachuk, D. Mailly and B. Barbara, Phys. Rev. Lett., 2001, 87, 057203; (b) M. Wu, F. Jiang, X. Kong, D. Yuan, L. Long, S. A. Al-Thabaiti and M. Hong, Chem. Sci., 2013, 4, 3104-3109; (c) M. Wu, F. Jiang, D. Yuan, J. Pang, J. Qian, S. A. Al-Thabaiti and M. Hong, Chem. Commun., 2014, 50, 1113-1115.

8 J. Yu and R. Xu, Acc. Chem. Res., 2010, 43, 1195-1204.

9 M. Wu, F. Jiang, X. Kong, D. Yuan, L. Long, S. A. Al-Thabaiti and M. Hong, Chem. Sci., 2013, 4, 3104-3109.

10 (a) X.-B. Han, Y.-G. Li, Z.-M. Zhang, H.-Q. Tan, Y. Lu and E.-B. Wang, J. Am. Chem. Soc., 2015, 137, 5486-5493; (b) J. C. G. Bunzli, Coord. Chem. Rev., 2015, 293, 19-47; (c) V. Velasco, D. Aguila, L. A. Barrios, I. Borilovic, O. Roubeau, J. Ribas-Arino, M. Fumanal, S. J. Teat and 
G. Aromi, Chem. Sci., 2015, 6, 123-131; (d) Y. Zhang, L. Huang, H. Miao, H. X. Wan, H. Mei, Y. Liu and Y. Xu, Chem. - Eur. J., 2015, 21, 3234-3241.

11 A. S. R. Chesman, D. R. Turner, B. Moubaraki, K. S. Murray, G. B. Deacon and S. R. Batten, Chem. - Eur. J., 2009, 15, 5203-5207.

12 (a) A. S. R. Chesman, D. R. Turner, B. Moubaraki, K. S. Murray, G. B. Deacon and S. R. Batten, Chem. - Eur. J., 2009, 15, 5203-5207; (b) B. Zhang, X. Zheng, H. Su, Y. Zhu, C. Du and M. Song, Dalton Trans., 2013, 42, 8571-8574; (c) K.-C. Xiong, F.-L. Jiang, Y.-L. Gai, D.-Q. Yuan, D. Han, J. Ma, S.-Q. Zhang and M.-C. Hong, Chem. - Eur. J., 2012, 18, 5536-5540; (d) R. McLellan, J. Reze, S. M. Taylor, R. D. McIntosh, E. K. Brechin and S. J. Dalgarno, Chem. Commun., 2014, 50, 2202-2204.

13 (a) S. K. Langley, B. Moubaraki and K. S. Murray, Inorg. Chem., 2012, 51, 3947-3949; (b) R. Sen, D. K. Hazra, M. Mukherjee and S. Koner, Eur. J. Inorg. Chem., 2011, 2011, 2826-2831.

14 P. C. Andrews, T. Beck, C. M. Forsyth, B. H. Fraser, P. C. Junk, M. Massi and P. W. Roesky, Dalton Trans., 2007, 5651-5654.

15 G. J. T. Cooper, G. N. Newton, P. Kögerler, D.-L. Long, L. Engelhardt, M. Luban and L. Cronin, Angew. Chem., Int. Ed., 2007, 46, 1340-1344.

16 X.-J. Kong, Y. Wu, L.-S. Long, L.-S. Zheng and Z. Zheng, J. Am. Chem. Soc., 2009, 131, 6918-6919.

17 (a) Y. Zheng, A. Ellern and P. Kogerler, Acta Crystallogr., 2011, 67, i56-i58; (b) Z. Fu, Y. Zheng, Y. Xiao, S. Bedanta, A. Senyshyn, G. G. Simeoni, Y. Su, U. Rücker, P. Kögerler and T. Brückel, Phys. Rev. B: Condens. Matter, 2013, 87, 214406; (c) Y.-C. Chen, L. Qin, Z.-S. Meng, D.-F. Yang, C. Wu, Z. Fu, Y.-Z. Zheng, J.-L. Liu, R. Tarasenko, M. Orendac, J. Prokleska, V. Sechovsky and M.-L. Tong, J. Mater. Chem. A, 2014, 2, 9851-9858; (d) Y.-Z. Zheng, G.-J. Zhou, Z. Zheng and R. E. P. Winpenny, Chem. Soc. Rev., 2014, 43, 1462-1475.

18 (a) X. Song, Y. Li, L. Gan, Z. Wang, J. Yu and R. Xu, Angew. Chem., Int. Ed., 2009, 48, 314-317; (b) Y. Wang, Y. Li,
Y. Yan, J. Xu, B. Guan, Q. Wang, J. Li and J. Yu, Chem. Commun., 2013, 49, 9006-9008.

19 L. Pauling, Z. Kristallogr., 1930, 74, 213-225.

20 (a) L. Sun, H. Xing, Z. Liang, J. Yu and R. Xu, Chem. Commun., 2013, 49, 11155-11157; (b) Y. Ban, Y. Li, Y. Peng, H. Jin, W. Jiao, X. Liu and W. Yang, Chem. - Eur. J., 2014, 20, 11402-11409; (c) C.-T. He, L. Jiang, Z.-M. Ye, R. Krishna, Z.-S. Zhong, P.-Q. Liao, J. Xu, G. Ouyang, J.-P. Zhang and X.-M. Chen, J. Am. Chem. Soc., 2015, 137, 7217-7223.

21 L. F. Wang, H. Li, G. S. Zhu, H. Ren, F. X. Sun and S. L. Qiu, Chem. J. Chin. Univ., 2008, 29, 2127-2130.

22 O. Delgado-Friedrichs and M. O'Keeffe, Acta Crystallogr., Sect. A: Fundam. Crystallogr., 2003, 59, 351.

23 (a) The Handbook of X-ray Photoelectron Spectroscopy, Perkin Elmer Corporation, 1979; (b) H. Xing, W. Yang, T. Su, Y. Li, J. Xu, T. Nakano, J. Yu and R. Xu, Angew. Chem., Int. Ed., 2010, 49, 2328-2331.

24 S. V. Krivovichev, O. Mentré, O. I. Siidra, M. Colmont and S. K. Filatov, Chem. Rev., 2013, 113, 6459-6535.

25 M. Wu, F. Jiang, X. Kong, D. Yuan, L. Long, S. A. Al-Thabaiti and M. Hong, Chem. Sci., 2013, 4, 3104-3109.

26 (a) Q. Chen, Y.-S. Meng, Y.-Q. Zhang, S.-D. Jiang, H.-L. Sun and S. Gao, Chem. Commun., 2014, 50, 10434-10437; (b) D.-D. Yin, Q. Chen, Y.-S. Meng, H.-L. Sun, Y.-Q. Zhang and S. Gao, Chem. Sci., 2015, 6, 3095-3101; (c) B. Monteiro, J. T. Coutinho, C. C. L. Pereira, L. C. J. Pereira, J. Marçalo, M. Almeida, J. J. Baldoví, E. Coronado and A. Gaita-Ariño, Inorg. Chem., 2015, 54, 1949-1957; (d) T. Han, J.-D. Leng, Y.-S. Ding, Y. Wang, Z. Zheng and Y.-Z. Zheng, Dalton Trans., 2015, 44, 13480-13484; (e) J. A. Quilliam, S. Meng and J. B. Kycia, Phys. Rev. B: Condens. Matter, 2012, 85, 184415.

27 Y.-Z. Zheng, Z. Zheng and X.-M. Chen, Coord. Chem. Rev., 2014, 258-259, 1-15.

28 SAINT, Bruker AXS Inc., 5465 East Cheryl Parkway, Madison, WI, 53711-5373, USA, 2000.

29 SHELXTL, Bruker AXS Inc., 5465 East Cheryl Parkway, Madison, WI, 53711-5373, USA, 2000. 